\section{El Efecto Kodak. De cómo la evolución de industria publicitaria puede significar su propia extinción}

\author{
Mónica Baquero Gaitán ${ }^{(1)}$ y Nohra
}

Ramírez Herrera ${ }^{(2)}$

\begin{abstract}
Resumen: La publicidad afronta cambios profundos por el impacto de la revolución tecnológica, la exigencia de efectividad y la urgencia de formación de profesionales con competencias aún por definir. Acerca de su evolución existen diversas lecturas de académicos estudiosos del fenómeno publicitario; el presente artículo se configura como un proyecto cuya intención es la comprensión de los retos que trae consigo la cuarta revolución industrial en el ejercicio de la profesión y en el estudio del fenómeno publicitario contemporáneo. Para ello, retoma las voces de publicistas de Iberoamérica y se indaga si la industria publicitaria como industria creativa está por reinventarse o si se enfrentan, el efecto Kodak o Blockbuster, propios de la obsolescencia del negocio.
\end{abstract}

Palabras clave: publicidad - cambio tecnológico - creatividad (Tesauro de la Unesco).

[Resúmenes en inglés y portugués en la página 66]

${ }^{(1)}$ Mónica Baquero Gaitán. Comunicadora Social de la Universidad de la Sabana. Magister en Comunicación de la Pontificia Universidad Javeriana. Candidata a doctora en Comunicación de la Universidad de la Plata se ha desempeñado como redactora publicitaria en agencias colombianas y en calidad de docente e investigadora en la Pontificia Universidad Javeriana, Politécnico Grancolombiano, Universidad Central y docente de cátedra en otras instituciones universitarias en el país; en la actualidad investiga acerca de las marcas y su relación con las transformaciones en torno al género, el consumo y el desarrollo sostenible. Mail: baquero-m@javeriana.edu.co

(2) Nohra Ramírez Herrera. Comunicadora Social y Magíster en Filosofía de la Pontificia Universidad Javeriana. Docente investigadora del programa de Publicidad de la Universidad Central y de la Universidad Javeriana. Especialista en Opinión Pública de la Universidad Pro-Deo, de Roma y en Dirección de Televisión de la Radio televisión italiana -RAI-, en Dramaturgia para Guiones Audiovisuales del Externado de Colombia y en Gerencia de Mercadeo Estratégico del Politécnico Grancolombiano. Se inició como copywriter de Leo Burnett-Venezuela hasta ser directora Creativa Regional para Procter \& Gamble. Fue directora editorial de la revista P\&M. Investiga en la marca y su relación con el ciudadano. Mail: nohra.ramirez@javeriana.edu.co 


\section{Introducción}

"Cuando todos hagan zig vos haces zag" Fernando Vega Olmos, 2019.

Blockbuster y Kodak dos empresas líderes en los mercados del siglo XX ya no existen; a pesar de su liderazgo no se adaptaron a los profundos cambios tecnológicos del siglo XXI; las dos empresas se confiaron de su estabilidad en el mercado, del producto o servicio que ofrecían y otros las desplazaron. Los consumidores se olvidaron del alquiler de películas en un local comercial y la creatividad e innovación permitió que los dispositivos móviles incluyan cámaras, algunas de ellas con alta resolución. Es tal el grado de sofisticación de los dispositivos que cualquier consumidor puede elaborar sus propios contenidos.

Vale agregar que la aparición de plataformas de video (cine) on demand tales como Netflix, Prime Video y más recientemente Amazon Prime y Disney+, entre otras, afecta en la actualidad el ecosistema publicitario no solo en la reducción de la pauta publicitaria en los canales tradicionales (vale decir canales de cable y canales locales o globales de TV estatal), sino en el cambio del modelo de negocio publicitario y, además, en la modificación de los hábitos de consumo del entretenimiento.

La publicidad como industria afronta el mismo riesgo ante la aparición de otros competidores en el mercado de la comunicación comercial como Accenture, empresa consultora de comunicación, Google, Facebook, Instagram, entre otros jugadores de la industria publicitaria en el mundo; Colombia y su industria publicitaria enfrenta los mismos retos que el negocio publicitario a nivel global. ¿Estamos ante el fin de la publicidad como la conocemos o asistimos a su reinvención por la revolución creativa y tecnológica?

Colombia ha sido reconocida como un país que se destaca en el mundo por su creatividad publicitaria debido a la creciente participación en los festivales internacionales. Es ya lejano el día en que Juan Carlos Ortiz, entonces presidente de Leo Burnett Colombia (hoy, presidente de DDB Latina) ganó en el año 2000, el Grand Prix de Cannes por el ya clásico comercial contra la droga. El premio que fue el segundo obtenido por el país, además, sentó las bases de una participación internacional constante que ha dado frutos tanto en reconocimiento al país como al talento creativo que es hoy un rubro de exportación.

De otra parte, el país cuenta con políticas públicas que impulsan la industria publicitaria. El Congreso de la República de Colombia expidió la Ley 1834 de 2017 con el objeto de desarrollar, fomentar, incentivar y proteger las industrias creativas, entendidas como aquellas industrias que generan valor a sus bienes y servicios fundamentados en la propiedad intelectual.

Ximena Tapias, directora de la UCEP, entidad que organizó y desarrolló el Congreso de Publicidad hoy llamado + Cartagena 2018 afirmó: "Queremos que Colombia sea el centro creativo en la región. Nos enfrentamos a un panorama lleno de grandes oportunidades, la región y el mundo pasaron por un momento complejo. Nuestro recurso natural regional es la creatividad" (Tapias, 2018, en Merca2.0, 2018).

Se suma a esta postura Iván Duque (2019) al afirmar en la Cumbre Latinoamericana de Economía Creativa "Más Cartagena" que a partir de los resultados de la medición realizada por la primera cuenta satélite de cultura y Economía Naranja; este sector "equivale 
al 1.8\% de Producto Interno Bruto, es decir casi el doble de lo que aporta la economía cafetera al país que es el 0.8 ".

Para Duque (2019) la importancia reside en que Colombia tiene recursos ilimitados en cuanto a la creatividad: Según lo afirmó en el Festival de creatividad de Cannes Lions en Francia, el capital más importante del país es el talento de su gente y la capacidad de convertir ese talento en un capital social y económico. La creatividad puede ser el acelerador del país; es decir el motor para transformar a Colombia en las décadas por venir (Duque, 2019 como se citó en Presidencia de la República, 2019).

La creatividad debe convertirse en el camino directo disponible para mejorar las condiciones de vida. Por esta razón, el BID -Banco Interamericano de Desarrollo- una de las principales fuentes de financiamiento a largo plazo para el desarrollo económico, social e institucional en América Latina y el Caribe, trabaja en la promoción de la llamada 'Economía Naranja', las actividades económicas relacionadas con la unión entre cultura, tecnología y comercio, bienes y servicios como cine, artes escénicas, música, diseño, animación y videojuegos.

Ante un panorama alentador, los profesionales de la industria publicitaria a nivel iberoamericano plantean cuestionamientos acerca de la sostenibilidad de dicha industria por la forma de operación y el ecosistema que la compone e incluso se preguntan si están viviendo el efecto Kodak o Blockbuster, propio de la obsolescencia del negocio. Entendiendo el fenómeno como aquella situación que vive una empresa cuando enfrenta problemas derivados de la falta de visión de sus dueños, directivos, gerentes o accionistas que los lleva a quedarse atrás de la evolución del mercado con consecuencias financieras nefastas. El presente artículo sistematiza algunas las entrevistas realizadas a 40 publicistas de Iberoamérica en el marco de Selfinterview ${ }^{1}$, un proyecto periodístico digital de Esteban Martucci $^{2}$, que reúne las entrevistas realizadas a los profesionales más reconocidos de Iberoamérica en festivales relevantes para la industria publicitaria. Ellos a través de su experticia y conocimiento de la industria dilucidan a través de sus respuestas los futuros posibles de la publicidad contemporánea como profesión e industria.

\section{Marco teórico}

"La publicidad es la industria de la promoción de la industria. Su función principal es promover el consumo de los productos industriales y conseguir que sustituyan a las costumbres populares" (Grupo Marcuse, 2009, p. 64).

Algunos teóricos de la publicidad se han permitido determinar etapas mediante las cuales delimitan la transformación, o evolución de la publicidad; mientras otros proponen las necesidades que sustentan su existencia. Según el grupo Marcuse, el capitalismo creó la publicidad por una triple necesidad. 
Primero, para dominar mercados nacionales y asegurarse de que lograran vender, más allá de los circuitos locales tradicionales, las inmersas cantidades producidas ya que el mercado no es un conjunto de clientes conocidos, sino una masa abstracta de consumidores lejanos. Segundo, para dar salida a los productos secundarios o residuales surgidos de nuevos procedimientos industriales que progresivamente ocupan el lugar de los hábitos de consumo de la población; así aparecen los cereales del desayuno, el aceite de cocina, entre otros productos.

El tercero, para diferenciar y valorizar productos industriales. Las nuevas técnicas de producción implican en efecto una estandarización considerable de los bienes de consumo corriente. Los publicistas tienen la misión de distinguir a los ojos de los consumidores, mercancías a las que ya casi nada, precisamente, distingue (Grupo Marcuse, 2009, pp.61-63). Una vez expuestos los argumentos que sustentan su existencia es necesario indagar por los cambios significativos en la publicidad. Según Franceso Casetti (1994) en la publicidad se infieren modelos comunicativos que sustentan su transformación. El primer modelo lo denomina Reclame; este aparece a finales del siglo XIX e inicios del siglo XX; consiste en la transmisión de información de producto a un receptor con procesos de simbolización, abstracción y un lenguaje directo. Mediante este modelo se exalta la riqueza de detalles de la mercancía, se le dota de una apariencia determinada que funciona como la imagen de marca y permite la circulación del mensaje y la mercancía (p. 23).

El segundo modelo comunicativo fue el Advertising, la edad de oro de la publicidad a finales de los años 30 hasta la década de los años sesenta; este se caracterizó por certificar la legitimidad del producto exaltando su intrínseca adecuación respecto al panorama de las necesidades sociales e individuales; en ese orden de ideas, se interpela a quien es el destinatario del mensaje y comprador de la mercancía; se le incita a descubrir la necesidad y a actuar apropiándose de los productos. Para ello se vale de los testimonios de las celebridades que implican al destinatario, quien finalmente es el protagonista del intercambio simbólico y económico; mediante la segunda persona del singular, la publicidad transforma al receptor en consumidor (p. 23, 24).

El tercer modelo comunicativo o Publicity, ha sido empleado desde las últimas décadas del siglo XX hasta nuestros días, consiste en certificar la colocación de los productos relacionándolos con un universo determinado en el cual se inserta de modo apropiado. Para tal fin se proponen palabras e imágenes que se ajusten a la naturaleza del producto o servicio y lo ubican en el universo vital del consumidor/ receptor mediante el marco de un estilo de vida que los englobe a ambos; desde esa perspectiva, la mercancía gana personalidad, construye un ambiente que lo hace identificable y con ello siempre está presente en un universo vital propio (p. 24, 25).

Otro autor que argumenta la transformación de la publicidad es Antonio Caro (2010); él sostiene que la publicidad ha vivido tres grandes revoluciones a lo largo de su historia. La primera revolución es el paso de la pequeña publicidad de productos a la gran publicidad de marcas. Para el autor, el paso de pequeños avisos publicitarios de columna por centímetro en la prensa a página entera marcó una etapa del oficio publicitario.

En un principio el negocio publicitaria se reducía a la intermediación entre los anunciantes y medios; intermediación de la agencia que suponía obtener los mejores precios por las inserciones para asegurar las correspondientes comisiones, dicha intermediación 
posteriormente se complejizó, porque los medios establecieron relación directa con los anunciantes y la actividad publicitaria paralelamente dejó de centrarse en la elaboración de mensajes de productos para pasar a la era de la marca/significación con lo cual la creatividad como trabajo fue colonizado por profesionales de otras ramas como la antropología, la sociología, entre otras disciplinas sociales de forma tal que el creativo asumió una función de catalizador de investigaciones, recursos y talentos para conseguir que productos idénticos fueran percibidos como distintos en función de la marca (p. 4).

En la Segunda revolución, una vez la televisión dejó de ser la extensión de lo que se hacía en el medio radial, logró su propio lenguaje y con ello amplificó sus posibilidades. Para Kevin Roberts citado por Caro (2012), un anuncio televisivo de treinta segundos es la herramienta que crea las conexiones emocionales más poderosas. Es una gran herramienta persuasiva. El comercial de televisión es una táctica publicitaria emblemática para cualquier marca que busque estar presente mediante una buena historia imponiendo la imagen sobre el texto (p. 7).

La tercera revolución, está constituida por el paso de lo análogo a lo digital. En sus inicios la publicidad interactiva permitió la comunicación bidireccional a través de internet que fue considerado como un nuevo medio y que posteriormente fue empleado como un entorno comunicativo que ha revolucionado la publicidad tradicional, porque el consumidor de medios ha pasado de ser un receptor a ser un usuario;" los medios masivos están en riesgo por la bidireccionalidad, un componente esencial de la nueva comunicación, y la pérdida del control del mensaje ya que ni el anunciante, ni los medios, ni los publicistas tienen el control de la comunicación" (Caro, 2012, p. 11).

Caro considera la publicidad una ideología que debe llevar al ser humano más del mero consumir, debe llevarlo al estado de Bienestar por lo que en reciente entrevista afirma que:

Hoy se debe realizar más un tipo de investigación que busque un mayor equilibrio y bienestar social. No realizar sólo investigación de mercado; es decir, sobre una determinada marca, envase o producto, sino investigar los impactos reales que tiene la publicidad, tanto en las personas como en la sociedad (Caro, 2021, p. 11).

Por su parte, Jesús Bermejo (2009) argumenta que el desafío de la publicidad contemporánea está en mantener viva y satisfacer esa vieja conexión entre el anunciante y su destinatario al ceder el espacio publicitario a nuevas formas publicitarias. Para el autor, la publicidad clásica está dejando de ser el sistema publicitario hegemónico, aunque este sistema, en su dimensión económico-cultural, sigue y seguirá vivo en nuevos espacios y cumpliendo nuevas funciones (p. 16).

Luego de una investigación publicada en 2020, el autor concluye que efectivamente uno de los grandes cambios que se advierten entre la publicidad clásica y la actual está en los modos de relacionarse el anunciante con el consumidor/receptor de la comunicación en tanto las nuevas tecnologías suponen que la publicidad haga uso de nuevas estrategias persuasivas con rasgos característicos diferenciados y que se integran en una unidad o estructura. Un conjunto que, "incluye piezas publicitarias y acciones de marketing” (Bermejo, 2020, p. 16). 
El autor afirma que:

En comparación con la publicidad clásica, la publicidad actual ha cambiado los modos de relación del anunciante con su público al introducir nuevas estrategias persuasivas que inducen niveles de tratamiento de la información publicitaria más profundos, desde el punto de vista de los procesos psicológicos activados durante la comunicación publicitaria. Ya no se trata sólo de captar su atención sino también de que haga alguna acción, se implique en conductas complejas, que participe en actividades creativas. Todo ello redunda en beneficio del anunciante pues, a mayor participación del usuario, mayor profundidad en el procesamiento de la información publicitaria y, en consecuencia, mayor almacenamiento en la memoria del mensaje publicitario (Bermejo, 2020, p. 17).

Desde otra perspectiva, Armand Mattelart (1991) Joan Costa (1992) y Sergio Zyman (2003) reconocen la reinvención de la industria publicitaria. Mattelart al divulgar que la publicidad ya no se trata de una comunicación unidireccional mediante la emisión de mensajes por medios masivos, sino de la inclusión de eventos con una activa participación de los consumidores. Joan Costa, al precisar que la comunicación corporativa integra y gestiona sinérgicamente las diferentes formas de comunicación empresarial, entre ellas la publicidad, un componente del ecosistema comunicativo de la empresa. Zyman, quien concluye que la publicidad supera los comerciales de televisión, cuñas de radio y avisos impresos e integra la marca como un todo porque comunica algo acerca de lo que hace a través del empaque hasta los eventos, los informes anuales, el material promocional y las noticias relacionadas con el manejo del negocio.

\section{Metodología}

A partir de un enfoque cualitativo, la investigación se realizó a partir de tres fases para dar cumplimiento a los objetivos planteados. Primero, comprender la evolución y transformación de la publicidad a partir de autores estudiosos de la publicidad. Para ello se realizó una revisión documental de los textos publicados por investigadores del fenómeno publicitario y de ellas extraen los que se consideran los hechos relevantes asociados a la evolución, transformación o reinvención de la publicidad.

Segundo. Analizar las entrevistas realizadas a 40 publicistas de Iberoamérica vinculados a la industria en el marco del proyecto digital Selfinterview teniendo en cuenta su trayectoria profesional en cargos de presidentes de agencia, creativos, digitales, planner, productores, ejecutivos de cuenta, entre otros.

Las entrevistas de Selfinterview se realizaron en los festivales publicitarios en 2017 y 2019 bajo un formato self que consiste en una entrevista de 5 hasta 20 minutos en los cuales, Esteban Martucci pone a su entrevistado frente a cámara bajo la promesa de decir la verdad y solo la verdad; en entrevistas realizadas bajo la modalidad de almuerzo de trabajo o 
webinars gratuitos con expertos de la industria en la plataforma Ourselves, una extensión de la anterior.

Para el análisis se tuvieron en cuenta los argumentos de los profesionales en los siguientes conceptos: el negocio que comprende la industria, la agencia, los anunciantes, los medios; la creatividad, esencia de la industria de las ideas y los premios que la valoran y finalmente, la tecnología y su incidencia en la transformación de la industria.

Finalmente, indagar sobre los retos y los futuros posibles de la publicidad contemporánea como profesión e industria a través de las reflexiones de los protagonistas en Iberoamérica. Valga la aclaración de que las entrevistas fueron realizadas en el Festival de Cannes 2017 en Francia, el Ojo e Iberoamérica 2017 en Argentina, El Dorado y Cartagena Inspira 2017 en Colombia; RP Latam 2017; + Cartagena 2018, Colombia, Cannes 2019 y en otras actividades realizadas en Argentina y a través de un webinar realizado con la Universidad Jorge Tadeo Lozano en el 2020 en plena pandemia en el mundo.

\section{Hallazgos y discusión}

De acuerdo con el análisis de las entrevistas publicadas en el portal de Selfinterview, materia de la presente investigación es válido afirmar con (Keller, 2017) que como él lo afirma: "Para los profesionales del negocio publicitario, la industria cambió desde que perdieron el manejo de los medios en las agencias. De tal manera, el nombre agencia obedece a que antes era el agentes comercial de un medio, con esa figura se pagaba lo pautado y no la idea; por ello, la remuneración está mal planteada desde los inicios de la industria, porque no se remunera el potencial de la idea; los anunciantes nunca van a pagar la idea y menos si existe una comisión sobre los medios (Agost, 2017, como se citó en Selfinterview, 2017). De acuerdo con ese planteamiento es válido destacar que la industria debe analizar cómo está cobrando las ideas, si es razonable mantener la lógica horas hombre a pesar de ser una industria creativa no ha podido encontrar una fórmula para replantearse (Pantigoso, 2017). Publicidad es generar soluciones de negocio para las marcas (Cardón, 2017), allí reside el valor de las ideas; la publicidad contemporánea es comunicación comercial por los resultados (Polar, 2017).

Es sabido que hoy las agencias están siendo atendidas por el departamento de compras y no por altos directivos de las empresas (Keller, 2017). En la actualidad, los anunciantes deben comprender que las agencias son indispensables por las ideas que ofrecen al anunciante (Sokoloff, 2017). Una gran idea es una verdad accionable para el consumidor, la categoría y la marca (Palette, 2017). La industria publicitaria debe recuperar el prestigio y el valor por las ideas que aporta; estas son un aporte económico que crea nuevos negocios a las marcas (Keller, 2017 como se citó en Selfinterview, 2020).

Según Posada (2017), Keller, (2017), Arslanian (2017) y Suez (2017) las agencias perdieron efectividad por tener una estructura organizacional que no les permite responder de manera ágil y oportuna. Consideran que es necesario retornar a la agencia integral mediante un modelo flexible que permita a los equipos un aporte constante a la construcción de la marca. Plantean que la reinvención de la agencia requiere un profundo análisis del 
negocio del anunciante sobre modelos econométricos, manejo de tecnología, relaciones públicas, digital, mercadeo móvil, creatividad y estrategia; ello implica la urgencia de otros talentos y perfiles profesionales. En Colombia, los directivos de las principales agencias, en comunicación personal con las autoras (2018) manifestaron que plantear una reinvención de la agencia también es una urgencia en el país debido a que cada vez los anunciantes exigen campañas con una mayor efectividad medida.

Sumado a lo anterior, la industria tiene otras amenazas en la actualidad; los clientes tienen sus agencias -in house-; los medios de comunicación también tienen las suyas. Hay muchos negocios que están inmiscuyéndose en la industria publicitaria (Ciro Sarmiento, 2017 como se citó en Selfinterview, 2017).

Las consultoras, son los nuevos jugadores en la industria publicitaria, encaran la evolución del negocio de la comunicación con una metodología que ve de manera integral el negocio del anunciante y la integración de diferentes disciplinas para la certera solución de un problema de marketing y de negocio de una marca. Son además socias del cliente con inversión; mientras las marcas ofrecen su experticia, la consultora desarrolla el canal, la operación de ventas, la inversión en medios, la gestión comercial online. Las consultoras tienen toda la experticia para hacerlo. La idea del negocio es trabajar con el anunciante a largo plazo, de manera real y profunda en la empresa, operando sobre su modelo de negocio, cartera, productos, servicios, donde sea posible mostrar un valor diferencial (Arslanian, 2017).

Se concuerda con el planteamiento de Ezequiel Arlanian, para quien las consultoras han transformado el negocio; hoy ocupan un espacio que no dominaron las agencias porque no han evolucionado y no han sabido entender el futuro. Por otro lado, las consultoras ofrecen una propuesta de valor y ahora son una categoría que compiten en el mercado con las agencias y trabaja para encontrar en soluciones a problemas de negocio del anunciante. Eso implica pensar en el talento, las soluciones, el impacto en el negocio de los clientes y la responsabilidad en el proceso.

El negocio publicitario es único y la evolución en el formato de solución para los anunciantes, lo tienen las consultoras. Ello obedece a que el modelo de las agencias de los holdings no cuenta con el talento que requiere el negocio y por tal razón quedaron estancadas. Las agencias de creativos están en otro negocio, son un nicho fuerte que entrega valor. El valor de este tipo de negocio es la creatividad (Ezequiel Arlanian, 2020, como se citó en Selfinterview, 2020)

En lo que respecta a los premios Keller (2017) y Polar (2017) afirman que estos contribuyen al desarrollo de las carreras de los profesionales de la industria; son el punto de partida de la carrera de un creativo y validación de un profesional, una empresa, un anunciante que la industria reconoce; por lo tanto, los premios hacen reputación y sirve tenerlos para tener credibilidad (Moro, 2017). Los premios son una métrica que tiene la industria para determinar quiénes son los mejores; la publicidad es una industria creativa que requiere valorar las buenas ideas (Vega, 2017, como se citó en Selfinterview, 2017), de manera que respecto a la cuestión de los premios es útil establecer que siguen siendo considerados el mecanismo de validación del talento creativo.

En cuanto a la tecnología, la automatización está llegando a territorios de la creatividad y no va a reducir su velocidad de crecimiento; se espera una revolución industrial que no 
permite transiciones, sino que exige inventar en tiempo real (Flores, 2017); sin embargo, Posada (2017) considera que la tecnología es una herramienta al servicio de lo que hace el ser humano e insiste en que no se le debe delegar el trabajo y menos los que requieren de procesos de pensamiento complejo. Para Forero (2017) las ideas deben ser implementadas a través de los recursos tecnológicos y coincide con Figueroa (2017) en que la tecnología no puede ir delante de las ideas, esencia del negocio publicitario contemporáneo.

Frente a lo digital, Santos (2017) afirma que el proceso de trabajo hoy requiere además de la idea, la producción total de la misma y recalca que lo digital es un cambio de mentalidad porque exige pensar de manera holística; pensar en conceptos, en formatos al servicio de la idea. Los creativos deber tener una formación basada en la cultura, ser creativo en sentido literal; gente intelectual con la capacidad técnica para llevar a cabo las ideas en diversos formatos (Santos, 2017); en ese sentido, la industria debe reflexionar en cuanto al perfil profesional requerido porque privilegiar la técnica y lo operativo va en detrimento del prestigio y rol de consultor del publicista, la agencia y la industria publicitaria.

Con respecto a los datos o data, los publicistas coinciden en que aporta al trabajo creativo. Para Bigio (2017) y Visco (2017) la data facilita información a un creativo para que la idea sea más impactante y a través de las cifras es factible constatar la resonancia que tiene la propuesta con relación a una conducta existente o revelar comportamientos de la gente que eran desconocidos. Ello implica una reflexión ética acerca de la interpretación de los datos al servicio del mercado por tratarse de un insumo preciado para el desarrollo creativo y estratégico; acerca de su uso en la toma de decisiones deberá primar un factor ético que la empresa y la industria está en mora de formular.

Finalmente, para Fernando Vega Olmos (2019) los holdings publicitarios son compañías financieras interesadas en cuidar los resultados financieros. Sin embargo, es necesario reconocer que en la industria publicitaria lo único que tiene valor es una idea diferenciadora independientemente del uso de la data, programática, inteligencia artificial que son herramientas complementarias. Por ello cuestiona la fascinación de las marcas con todo lo que la tecnología ofrece e invita a volver emplear la estrategia de la diferenciación que se logra exclusivamente con las ideas (Vega Olmos, 2019, como se citó en el programa de la publicidad, 2019).

Argumento que reiteran, Esteban Martucci (2020) y Francisco Samper (2020) al afirmar que uno de los grandes errores en la industria fue pensar que la publicidad debía migrar a lo digital, hoy el mundo es digital. Las ideas son la esencia de la industria publicitaria y sin una ejecución relevante en cualquier formato sin insignificantes.

En la actualidad, las agencias tienen que pensar en el negocio del cliente, en la forma de expresar el propósito de las marcas, en las ideas propuestas por el talento de agencia y con una ejecución que sobresalga. La era digital trajo consigo más trabajo y menos ganancia; sustituyó la concepción de las ideas y una estrategia consistente, en una referencia visual para la campaña y facturación, sin pensar en los resultados. Hay que volver al origen. A la esencia de la publicidad. A las ideas para transformar un nombre en una marca significativa para la gente (Fernando Vega Olmos, 2020, como se citó en Ourselves, 2020). 


\section{Consideraciones finales}

La industria publicitaria padece su momento Kodak y debe reacomodarse; hoy está la posibilidad de no comprar medios necesariamente para hacer comunicación. Hoy el contenido puede vivir en un motón de lugares que son gratis; la excusa del costo de la pauta en medios se acabó (Fernando Vega Olmos, 2017, como se citó en Selfinterview, 2018).

Para los profesionales de la industria, la publicidad está en momento de quiebre porque lo que se entendía como publicidad ha perdido relevancia; la publicidad, como industria y profesión, está siendo removida de su zona de confort. La comisión de medios ya no sostiene la industria, el pago mensual por un paquete de servicios para el anunciante no es rentable. Las ideas son el centro del negocio publicitario y las competencias de formación de profesionales aún están por definir.

Por tanto, una de las primeras tareas que debe asumir de la industria publicitaria es la reinvención de la agencia; su objetivo sigue siendo crear y vender las ideas que son su razón de ser y por las cuales los anunciantes deben pagar. Dejar de ser agencia para ser consultora requiere análisis sobre modelos econométricos, conocimiento profundo del negocio del cliente además del manejo de la comunicación de las marcas y ello exige profesionales e intelectuales con altas capacidades de análisis, argumentación y capacidad de solucionar de problemas comunicativos complejos. Y, una segunda tarea, no menos importante es la de modificar el pago de los servicios en comunicación por el pago de las ideas manteniendo los derechos de autoría sobre ellas.

Las agencias deben ser consideradas como espacios de creación de ideas para las marcas; la idea sigue siendo y será siempre el núcleo de la publicidad. Publicidad es generar soluciones de negocio para las marcas (Cardón, 2017). Frente a este aspecto el gremio publicitario a través de la Unión Colombiana de Empresas Publicitarias UCEP está en mora de emprender la misión de abrir el debate en las instancias gubernamentales correspondientes. Desde esa perspectiva, la publicidad entra a jugar un papel significativo en la Economía Naranja estimulada por el gobierno nacional y organismos internacionales. Los modelos económicos, políticos y sociales experimentados hasta ahora han sido insuficientes para resolver los principales problemas de la humanidad, por lo que la creatividad y la innovación pueden ser el sustento de una sociedad que enfrenta tiempos de incertidumbre, cambio acelerado y necesidad de redefinición.

La premisa fundamental de hoy, aceptada como verdad, dice que la economía global se está transformando; pasar del modelo industrial, basado en el capital y la mano de obra, a un modelo basado en el conocimiento y la creatividad. En este contexto, la innovación, el conocimiento y el talento son los recursos principales, en lugar de las materias primas y el capital. Así como en la era industrial, los capitalistas y los trabajadores asalariados eran las clases principales o los grupos económicos; la nueva economía del conocimiento también tiene dos clases principales de trabajadores: la clase creativa y la clase de servicio.

Para la UNCTAD, agencia de Naciones Unidas para el Comercio y el Desarrollo, no hay una única definición que recoja a la Economía Creativa; se trataría más bien de un concepto en constante evolución que se fundamenta en la creación y el talento humanos y en su relación con las ideas, la propiedad intelectual, el conocimiento y la tecnología. Nótese 
entonces que es un concepto contemporáneo y que está asociado a una plataforma y a un ecosistema digital.

Según el Índice de Creatividad Global, la clase de creatividad en los países desarrollados representa más del $40 \%$ de la fuerza laboral, que incluye científicos, ingenieros, artistas, medios de comunicación y entretenimiento, así como profesionales del sector de derecho, negocios, educación y salud. Por otro lado, existe el tipo de "servicios", que incluye restaurantes, alimentos, salud y otros proveedores de servicios. Esta clase es más grande, pero requiere menos habilidades, por lo tanto, se paga menos. La desigualdad entre estos dos grupos es muy similar a la que existía entre los capitalistas y los trabajadores en la economía industrial.

La creatividad debe convertirse en el camino directo hacia la mejorara de las condiciones de vida. Por esta razón, el BID - Banco Interamericano de Desarrollo - una de las principales fuentes de financiamiento a largo plazo para el desarrollo económico, social e institucional en América Latina y el Caribe, trabaja en la promoción de la llamada 'Economía Naranja'; las actividades económicas relacionadas con la unión entre cultura, tecnología y comercio, bienes y servicios como cine, artes escénicas, música, diseño, animación y videojuegos.

La misión ahora para la industria es comprender que los cambios que vive obedecen a múltiples factores, no solo el impacto tecnológico; se trata también del comportamiento humano (Ortiz, 2017). Las migraciones hacen que los mercados sean multiculturales, la inversión y la publicidad deben enfocarse a este tipo de fusión (Sarmiento, 2017). Los países del mundo afrontan la configuración de otro tipo de sociedades producto de la hibridación cultural.

Otro de los puntos críticos está en aceptar que los medios impresos siguen vigentes. La prensa o marcas de la información tienen un gran peso en los programas radiales, la televisión y están presentes en el mundo digital; las polémicas y los temas del día surgen a partir de la agenda noticiosa de los medios impresos (Ivaner, 2017). A pesar de las ideas apocalípticas acerca de su existencia y sostenibilidad, los medios tradicionales son parte del ecosistema publicitario.

Selfinterview como proyecto de innovación periodística permite un conocimiento de la industria publicitaria que se caracteriza por el hermetismo y un enorme distanciamiento de la académica; emplear los contenidos para la comprensión de la publicidad y la profesión en los espacios académicos ubica a los profesionales en formación en el negocio de ideas para las marcas y les permite tener un amplio panorama del ejercicio profesional. Las voces de los publicistas de Iberoamérica nutren las discusiones y debates en el aula de clase y eliminan la brecha entre el saber académico y el saber basado en la experiencia del ejercicio profesional.

Es sabido que la pandemia ocasionada por el Covid 19 ha afectado la vida del consumidor en todo el planeta y las marcas han tenido que adaptarse incluso reconfigurando su manera de legitimarse en la sociedad propendiendo por iniciativas cuyo destinatario al final es el hombre, lo importante de resaltar es que esta afectación pone aún más en evidencia la crisis que atraviesa la industria publicitaria y pone en tela de juicio las promesas de la Economía Naranja. 


\section{Notas}

1. Según el perfil de Linkedin de su creador, Selfinterview es un proyecto de innovación periodística en que se retratan las personalidades de los creativos más importantes del mundo de habla hispana. Un medio digital cuyo contenido se reproduce en los blogs publicitarios de Argentina, México, Colombia, Perú, Estados Unidos y mercado hispano.

2. El perfil de Linkedin de Esteban Martucci destaca los siguientes logros de su carrera profesional: hizo parte de la generación de creativos argentinos que revolucionó la creatividad en ese país; profesor universitario; asesor creativo de agencias y de clientes.

\section{Referencias bibliográficas}

Agost, C. (2017). Selfinterview. Classic César Agost Carreño. [Archivo de Vídeo] Youtube. http://selfinterview.com/people.php?id=12

Arslanian, E. (2017). Selfinterview. ¿Qué tiene en la cabeza Ezequiel Arslanian? [Archivo de Vídeo] Youtube. http://selfinterview.com/people.php?id=46

Ávila, R. (2018, 9 de junio). Así se mueve la publicidad en Colombia. Dinero. https://www. dinero.com/opinion/columnistas/articulo/asi-se-mueve-la-publicidad-en-colombiapor-raul-avila/259956

Bermejo, B. J. (2020). Las nuevas estrategias persuasivas publicitarias por inducción de niveles de procesamiento psicológico. En Revista Mediterránea de Comunicación, 3 (2), 9-16. https://revistas.ucm.es/index.php/PEPU/article/view/PEPU0909220009A/15313

Bigio, G. (2017). Selfinterview. Classic Gastón Bigio. [Archivo de Vídeo] Youtube. http:// selfinterview.com/people.php?id=24

Caro, A. (12 de mayo 2010). ¿Realmente estamos asistiendo al final de la publicidad? [Discurso principal] IV Congreso Galería Publicitaria, Cali, Universidad Autónoma de Occidente, Colombia. http://www.reddircom.com/textos/estamos_asistiendo.pdf . (2021). El bienestar no proviene de consumir más: revista digital Suplemento Campus. https://suplementocampus.com/el-bienestar-no-proviene-de-consumirmas-antonio-caro-publicista-en-la-udec/

Cardos, R. (2018). Selfinterview. Classic Raúl Cardos. [Archivo de Vídeo] Youtube. http:// selfinterview.com/people.php?id=7

Casetti, F. «Modelos comunicativos de la publicidad». Questiones publicitarias, [en línea], 1994, Vol. 1, n. ${ }^{\circ}$ 2, pp. 22-33, https://raco.cat/index.php/questionespublicitarias/article/ view/350014

Costa, J. (1992). Reinventar la publicidad. Madrid: Fundesco.

Figueroa, R. (2017). Selfinterview. Classic Rodrigo Figueroa Reyes. [Archivo de Vídeo] Youtube. http://selfinterview.com/people.php?id=6

Flores, E. (2017) Selfinterview. ¿Qué tiene en la cabeza Emmanuel Flores? [Archivo de Vídeo] Youtube. http://selfinterview.com/people.php?id=41

Forero, J.R. (2017). Selfinterview. Classic John Raúl Forero. [Archivo de Vídeo] Youtube. https://www.youtube.com/watch?v=9LyG42E6UP4 
Grupo Marcuse (2009). De la miseria humana en el medio publicitario. España: Editorial Melusina.

Ivanner, M. (2017). ¿Qué tiene en la cabeza Mariela Ivanier? [Archivo de Vídeo] Youtube. http://selfinterview.com/people.php?id=27

Keller, S. (2017). Self contents. [Archivo de Vídeo] Youtube. http://selfinterview.com/ people.php?id=62

Ley 1834. Diario Oficial. Año CLIII No. 50.242. Bogotá, Colombia, 23 de mayo de 2017. Pág. 1.

Martucci, E. (2019). Esteban Martucci. Fundador y director en Selfinterview. [Archivo de Vídeo] Youtube. https://ar.linkedin.com/in/esteban-martucci-0b3a1313

Mattelart, A. (1991). La Publicidad. Barcelona: Paidós.

Merca2.0. (13 de abril de 2018). Ximena Tapias en Merca2.0 mercadotecniapublicidad medios [Archivo de Vídeo]. Youtube. https://www.youtube.com/watch?v=Rw4chaFhzP4

Ministerio de Cultura. (2020). ABC Economía Naranja [Archivo PDF). https://www.min cultura.gov.co/prensa/noticias/Documents/atencion-al-ciudadano/_ABC_ECONOMI $\%$ CC\%81A_NARANJA_pdf

Moro. M. (2007). Selfinterview. ¿Qué tiene en la cabeza Mónica Moro? [Archivo de Vídeo]. Youtube. http://selfinterview.com/people.php?id=63

Ortiz, J. C. (2017). Selfinterview. ¿Qué tiene en la cabeza Juan Carlos Ortiz? [Archivo de Vídeo]. Youtube. http://selfinterview.com/people.php?id=59

Palette, A. (2017). Selfinterview. ¿Qué tiene en la cabeza Alex Pallete? [Archivo de Vídeo]. Youtube. http://selfinterview.com/people.php?id=18

Pantigoso, F. (2017). ¿Qué tiene en la cabeza Flavio Pantigioso? [Archivo de Vídeo]. Youtube. http://selfinterview.com/people.php?id=28

Polar, H. (2007). Selfinterview. Classic Humberto Polar. [Archivo de Vídeo] Youtube. http:// selfinterview.com/people.php?id=2

Posada, J. J. (2017). Selfinterview. ¿Qué tiene en la cabeza Juan José Posada? [Archivo de Vídeo] Youtube. http://selfinterview.com/people.php?id=14

Presidencia de la República. (21 de junio de 2019). Iván Duque conferencia “The orange Economy: How Ideas are the new oil" [Archivo de Vídeo]. Youtube. https://www.youtube. com/watch? $=$ NwYLSYdn0EE

Presidencia de la República. (4 de octubre de 2019). Iván Duque en la Cumbre Latinoamericana Economía Creativa "Más Cartagena” [Archivo de Vídeo]. Youtube. https://www. youtube.com/watch?v=gihkS2Ov6ww

Santos, E. (2017). Selfinterview. Classic Eva Santos. [Archivo de Vídeo] Youtube. http:// selfinterview.com/people.php?id=22

Sarmiento, C. (2017). Selfinterview. ¿Qué tiene en la cabeza Ciro Sarmiento? [Archivo de Vídeo] Youtube. http://selfinterview.com/people.php?id=65

Selfinterview. (17 de febrero de 2020). Almuerzo en Moby Dick. Capítulo \# 7. Entrevista. http://selfinterview.com/

Sokoloff. J. M. (2017). Selfinterview. Classic José Miguel Sokoloff. [Archivo de Vídeo] Youtube. http://selfinterview.com/people.php?id=39

Suez, J. y Suez, M. (2017). Selfinterview. ¿Qué tienen en la cabeza Javier y Mariano Suez? [Archivo de Vídeo] Youtube. http://selfinterview.com/people.php?id=58 
Vega. F. (2018) Selfinterview. Classic Fernando Vega Olmos. [Archivo de Vídeo] Youtube. http://selfinterview.com/people.php?id=1

Vega, F.; Martucci, E.; Samper, F. y Novoa A. (2020). Ourselves. Dilemas del negocio publicitario. [Archivo de Vídeo] Youtube. https://ourselvesonline.com/el-arte-y-el-negocioen-la-publicidad/

\begin{abstract}
Advertising faces profound changes due to the impact of the technological revolution, the demand of effectiveness and the urgency of training professionals with competencies yet to be defined. Scholars who study the advertising phenomenon have different readings of it. This article presents as a classroom project whose intention is to understand the challenges brought about by the fourth industrial revolution in the exercise of profession and the study of the contemporary advertising phenomenon. In order to do so, it takes up the voices of advertisers in Latin America and inquires whether the advertising industry as a creative industry is about to reinvent itself or if it faces the Kodak or Blockbuster effect, typical of the obsolescence of the business.
\end{abstract}

Keywords: advertising - technological changes - creativity.

Resumo: A publicidade passa por mudanças profundas devido ao impacto da revolução tecnológica, à exigência de eficácia e à urgência de formar profissionais com competências ainda por definir. Sobre sua evolução existem várias leituras por acadêmicos do fenômeno publicitário; Este artigo configura-se como um projeto cuja intenção é compreender os desafios que a quarta revolução industrial traz consigo no exercício da profissão e no estudo do fenômeno publicitário contemporâneo. Para isso, toma a voz de publicitários latino-americanos e investiga se a indústria publicitária como indústria criativa está prestes a se reinventar ou se enfrenta o efeito Kodak ou Blockbuster, típico da obsolescência do negócio.

Palavras chave: publicidade - mudança tecnológica - criatividade.

[Las traducciones de los abstracts fueron supervisadas por el autor de cada artículo] 